\title{
NDC GR (Gram)
}

National Cancer Institute

\section{Source}

National Cancer Institute. NDC GR (Gram). NCI Thesaurus. Code C155841.

A recognized billing qualifier that may be used to identify a unit as the NDC unit of measure. This is often used when describing ointments, creams, inhalers or bulk powder in a jar. 